\title{
COMPARISON OF THE EFFECTS OF TRANSFUSIONS OF CRYOPRESERVED AND LIQUID-PRESERVED PLATELETS ON HEMOSTASIS AND BLOOD LOSS AFTER CARDIOPULMONARY BYPASS
}

Shukri F. Khuri, MD

Nancy Healey, BS ${ }^{\mathrm{a}}$

Hollace MacGregor, BS ${ }^{c}$

Marc R. Barnard, MS ${ }^{\mathrm{b}}$

Irma O. Szymanski, MD

Vladimir Birjiniuk, $\mathrm{MD}^{\mathrm{a}}$

Alan D. Michelson, MD $^{\mathrm{b}}$

David R. Gagnon, MD, MPH, $\mathrm{PhD}^{\mathrm{d}}$

C. Robert Valeri, $\mathrm{MD}^{\mathrm{c}}$
Objective: The aim of the study was to compare the clinical effects and hemostatic efficiency of transfusions of platelets preserved in the frozen state for as long as $\mathbf{2}$ years with transfusions of platelets preserved in the conventional manner for as long as $\mathbf{5}$ days in patients undergoing cardiopulmonary bypass. Methods: Seventy-three patients were prospectively randomly assigned to receive transfusions of cryopreserved or liquidpreserved platelets. Nonsurgical blood loss was measured during and after the operation. Bleeding time, hematologic variables, and the bleeding time site shed blood were assayed before cardiopulmonary bypass and at 30 minutes and 2, 4, and 24 hours after transfusion. In vitro platelet function tests were conducted on platelets obtained from healthy volunteers. Results: No adverse sequelae of the transfusions were observed. Blood loss and the need for postoperative blood product transfusions were lower in the group receiving cryopreserved platelets. Lower posttransfusion platelet increments and a tendency toward decreased platelet survival were observed in patients receiving cryopreserved platelets. Hematocrit and plasma fibrinogen were significantly higher in this group, and the duration of intubation was shorter. In vitro, cryopreserved platelets demonstrated less aggregation, lower $\mathbf{p H}$, and decreased response to hypotonic stress but generated more procoagulant activity and thromboxane. Conclusions: (1) Cryopreserved platelet transfusions are superior to liquid-preserved platelets in reducing blood loss and the need for blood product transfusions after cardiopulmonary bypass. (2) The reduction in blood loss in the patients receiving cryopreserved platelet transfusions after cardiopulmonary bypass probably reflects improved in vivo hemostatic function of cryopreserved platelets. (3) Some in vitro measures of platelet quality (aggregation, pH, hypotonic stress) may not reflect in vivo quality of platelet transfusions after cardiopulmonary bypass, whereas other in vitro measures (platelet procoagulant activity and thromboxane) do. (J Thorac Cardiovasc Surg 1999;117:172-84)
T he institution of cardiopulmonary bypass (CPB) elicits a hemostatic defect that leads to increased blood loss after cardiac operations. ${ }^{1,2}$ Because the CPB-

From the Department of Surgery, Brockton/West Roxbury Veterans Administration Medical Center, Brigham and Women's Hospital, Harvard Medical School, Boston, ${ }^{\text {a }}$ the Center for Platelet Function Studies, Department of Pediatrics, Surgery, and Laboratory Medicine, University of Massachusetts Medical Center, Worcester, ${ }^{\mathrm{b}}$ the Naval Blood Research Laboratory, Boston University School of Medicine, Boston, Boston University School of Public Health, ${ }^{c}$ and the Massachusetts Veterans Epidemiology Research and Information Center, ${ }^{\mathrm{d}}$ Boston, Mass.

Supported by the US Navy (Office of Naval Research Contract N00014-94-C-0149), with funds provided by the Naval Medical Research and Development Command, and the Richard Warren Surgical Research and Educational Fund, Westwood, Mass. induced hemostatic dysfunction is related in part to platelet dysfunction, ${ }^{3}$ platelet transfusion therapy has been a major component in the management of bleed-

The opinions or assertions contained herein are those of the authors and should not be construed as official or reflecting the views of the Navy Department or Naval Service at large.

Received for publication Feb 5, 1998; revisions requested March 24, 1998; revisions received Aug 10, 1998; accepted for publication Aug 10, 1998.

Address for reprints: Shukri F. Khuri, MD, Surgical Service, Brockton/West Roxbury VA Medical Center, 1400 VFW Parkway, West Roxbury, MA 02132.

$12 / 1 / 93782$ 
ing after CPB. The current method of liquid storage of platelets at room temperature limits the duration of their clinical use to 5 days and results in a progressive decline in platelet survival during this period. ${ }^{4}$ Cryopreservation, which allows storage of the platelets for as long 2 years, represents an alternative strategy for maintaining an adequate inventory of platelets. Cryopreserved platelets have reduced recovery and survival in vivo and impaired response to in vitro testing compared with liquid-preserved platelets. ${ }^{5-9}$ However, platelet recovery and survival in vivo do not correlate with the in vivo hemostatic function of transfused platelets. ${ }^{10}$ Cryopreserved platelet transfusions have demonstrated therapeutic effectiveness ${ }^{6,11}$ but have not been reported on in the setting of CPB. No randomized trials in any clinical setting have addressed the in vivo hemostatic effectiveness of cryopreserved platelet transfusions compared with that of liquid-preserved platelet transfusions.

The CPB-induced hemostatic defect offers a unique opportunity for the assessment of the hemostatic effectiveness in vivo of specific interventions because it results in postoperative blood loss, a quantifiable variable that relates directly to the magnitude of the CPBinduced hemostatic dysfunction. ${ }^{1}$ This paradigm has been effectively employed in numerous studies that have demonstrated the hemostatic efficacy of pharmacologic agents, such as aprotinin, by demonstrating their efficacy in reducing blood loss after CPB. ${ }^{12}$ This study was designed to assess the comparative effects on hemostasis and blood loss of liquid-preserved and cryopreserved platelet transfusions obtained from healthy volunteers and administered to patients after complex cardiac operations. The study also provides a comparison between the in vivo hemostatic effect and the in vitro function of both liquid-preserved and cryopreserved platelet transfusions.

\section{Methods}

Study protocol. After institutional review board approval was obtained, this investigation was performed on 73 patients undergoing cardiac operations at the West Roxbury Veterans Administration Medical Center. Informed consent was obtained from patients scheduled to undergo 1 of a predefined list of complex cardiac surgical procedures. Inclusion criteria were as follows:

1. Patient was scheduled for reoperative valve replacement, reoperative coronary artery bypass grafting, or both.

2. Patient was scheduled for primary valve replacement combined with coronary artery bypass grafting.

3. Valve replacement was scheduled for a patient with a platelet count of $\leq 150,000 / \mu \mathrm{L}$.
4. An operation with $\mathrm{CPB}$ was to be performed on a patient with a preoperative intra-aortic balloon pump and a platelet count $\leq 100,000 / \mu \mathrm{L}$.

These operations were chosen because they were anticipated to require a prolonged period of CPB and also because a review of the institution's previous experience had revealed a high likelihood of their resulting in platelet transfusions. The operations were performed by 2 surgeons (S.F.K. and V.B.) employing a similar technique for CPB under moderate systemic hypothermia. A centrifugal pump and a membrane oxygenator were used in the circuit. No prophylactic antifibrinolytic therapy (eg, aprotinin, $\varepsilon$-aminocaproic acid) was administered. Systemic anticoagulation was achieved with an initial heparin dose of $3 \mathrm{mg} / \mathrm{kg}$ body weight and maintained with the activated clotting time (ACT) during $\mathrm{CPB}$ longer than 480 seconds. After weaning from CPB and decannulation, heparin was neutralized with protamine sulfate given in a ratio of $0.5 \mathrm{mg}$ of protamine to $1.0 \mathrm{mg}$ of the initial heparin dose and $1.0 \mathrm{mg}$ of protamine to $1.0 \mathrm{mg}$ of heparin for any subsequent doses. Reversal of the heparin effect was determined by the return of the ACT to baseline level. At this time measurement of the blood loss was started, and the platelet transfusion previously determined by the randomization process was given unless the magnitude of the diffuse oozing from the tissues was determined by the surgeon to be minimal. Throughout both the intraoperative and postoperative courses, the surgeon, the anesthesiologist, and all individuals involved with ordering blood products during the patient's postoperative course were kept blinded to the type of platelets randomly selected for transfusion. The need for transfusion of red blood cells, fresh-frozen plasma, or further platelets was determined by the house staff after consultation with the attending surgeon, in accordance with set protocols that involved the observed blood loss and the patient's hemoglobin, hematocrit, and prothrombin time. A record was kept of all blood products received after CPB including unwashed shed mediastinal blood that was collected in the chest tube Pleur-evac collecting system (Deknatel, Inc, Fall River, Mass) and routinely reinfused in all patients.

Measurement of postoperative blood loss. Measurement of blood loss was started in the operating room when the ACT returned to baseline after the administration of protamine. In the absence of specific localized surgical bleeding, the generalized blood loss after the neutralization of heparin was assumed to be reflective of the patient's hemostatic state and was termed nonsurgical blood loss. To ensure that the blood measured represented nonsurgical blood loss, patients in whom specific surgical bleeding was encountered after the neutralization of heparin were prospectively excluded from the analysis. In addition, fluid irrigation was avoided during the closure of the chest so as not to interfere with the weight of the sponges. If irrigation was necessary, the fluid used was aspirated separately and sponges were not used during the irrigation. In the postoperative period, patients who had to undergo reexploration for control of bleeding were also excluded from the analysis. 


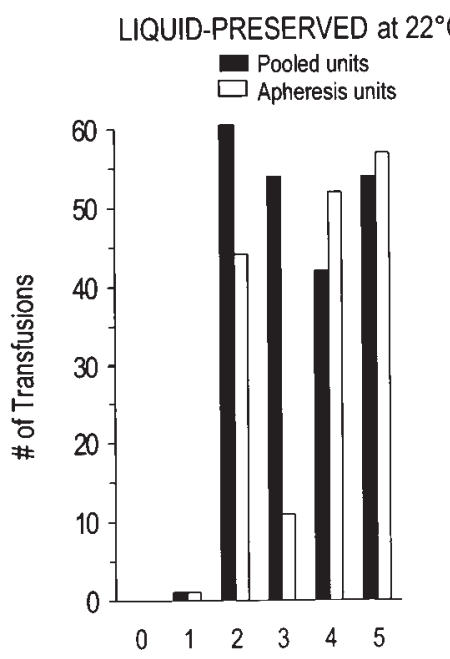

CRYOPRESERVED at $-80^{\circ} \mathrm{C}$

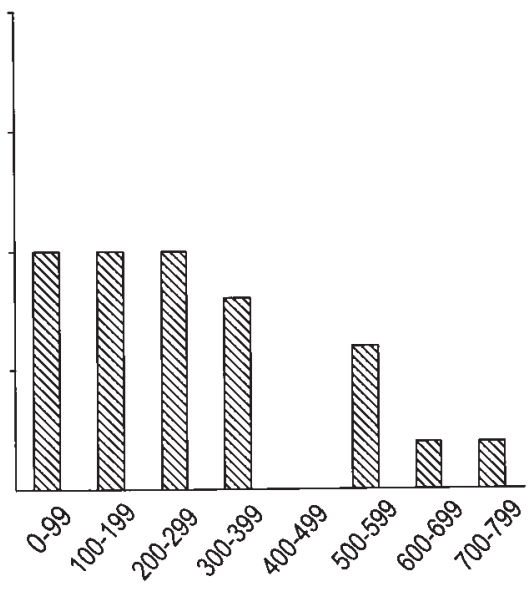

Length of Storage (Days)

Fig 1. Number of platelet transfusions administered and length of storage (days) of liquid-preserved pooled platelets at $22^{\circ} \mathrm{C}$, liquid-preserved apheresed platelets at $22^{\circ} \mathrm{C}$, and cryopreserved platelets at $-80^{\circ} \mathrm{C}$.

A dedicated research assistant measured the blood loss starting from the time of the neutralization of heparin. This included all the blood aspirated from the surgical field through wall suction and through a Cell Saver apparatus (Haemonetics Corp, Braintree, Mass). It also included the blood contained in the sponges and laparotomy pads used in the operative field. These were accurately weighed and their blood content was calculated by subtracting the standardized dry weights from the actual wet weights. The differences in the weight of the sponges and pads were converted into milliliters of blood loss in accordance with the formula described by Van Slyke and associates. ${ }^{13}$

Chest tube drainage was measured as soon as the chest tubes were placed during the operation, and this measurement was continued until the patient was transferred out of the operating room. The blood loss measured to this point constituted the intraoperative component of the blood loss. Subsequent chest drainage in the surgical intensive care unit constituted the postoperative component of the blood loss.

Platelet products. All donors met the requirements of the American Association of Blood Banks for healthy donors.

Cryopreserved platelets. The platelet cryopreservation method has been previously described elsewhere. ${ }^{6}$ It is summarized in the Appendix. The total length of storage (mean $289 \pm 193$ days) at $-80^{\circ} \mathrm{C}$ of the frozen platelets is shown in Fig 1 . The mean in vitro platelet recovery after thawing, washing, and resuspension of the 68 units transfused to patients, as determined by phase microscopy, was $70 \% \pm 18.4 \%$.

Liquid-preserved platelets. Two types of liquid-preserved platelets were used in this study, pooled platelets and platelets obtained by apheresis. The methods of preparation of these platelets are described in the Appendix. Patients randomly assigned to receive liquid-preserved platelets received either type of platelet transfusion according to the availability in the blood bank.

Recovery of transfused platelets. The total number of platelets transfused was determined by multiplying the volume of the product transfused times the product's platelet count per milliliter. The patient's blood volume was estimated from the body surface area, and peripheral blood platelet count was measured with the Coulter model JT automated cell-counting system (Coulter Electronics, Hialeah, Fla). The total platelet increment after transfusion at each time interval was determined by the increase in the absolute peripheral blood platelet count compared with the pretransfusion value times the total blood volume. The percentage recovery of the transfused platelets was determined by the total increment divided by the total number of platelets transfused.

Recovery $(\%)=[($ Total blood volume $[$ Posttransfusion platelet count $/ \mathrm{mL}$ - Pretransfusion platelet count $/ \mathrm{mL}]$ ) / (Total number of platelets transfused) $] \times 100 \%$

Hematologic assays. Arterial blood was drawn into tripotassium ethylenediaminetetraacetic acid-containing tubes for measurement of hematocrit, hemoglobin, platelet count, white blood cell count, and mean platelet volume with an electronic particle counter (Coulter model JT) ${ }^{14}$; and into sodium citrate-containing tubes for measurement of fibrinogen, factor V, and factor VIII with an automated coagulation system (Organon Teknika Corp, Durham, NC), ${ }^{15}$ of fibronectin by an immunoturbidometric assay, ${ }^{16}$ of heparin by a chromogenic assay, ${ }^{17}$ and of D-dimer by an enzyme-linked immunosorbent assay. ${ }^{18}$ Serum was obtained from a tube containing no anticoagulant for measurement of albumin measured using an automated chemistry analyzer (Cobas; Roche Diagnostic Systems, Inc, Branchburg, NJ). ${ }^{19}$ 
Table I. Patient characteristics

\begin{tabular}{|c|c|c|c|}
\hline & $\begin{array}{l}\text { Liquid-preserved } \\
\qquad(n=29)\end{array}$ & $\begin{array}{c}\text { Cryopreserved } \\
(n=24)\end{array}$ & $\mathrm{P}$ \\
\hline Age (y) & $62.9 \pm 8.0$ & $63.4 \pm 8.1$ & $>.2$ \\
\hline Preoperative hematocrit (\%) & $33.6 \pm 5.0$ & $34.8 \pm 4.7$ & .20 \\
\hline Preoperative bleeding time (min) & $6.8 \pm 2.8$ & $6.9 \pm 3.2$ & $>.2$ \\
\hline Preoperative ejection fraction (\%) & $52 \pm 13$ & $55 \pm 16$ & $>.2$ \\
\hline Preoperative prothrombin time (s) & $14.1 \pm 7.0$ & $13.2 \pm 3.4$ & $>.2$ \\
\hline Preoperative partial thromboplastin time (s) & $36.5 \pm 19.1$ & $33.8 \pm 14.2$ & $>.2$ \\
\hline Platelet count $\left(10^{3}\right.$ cells $\left./ \mathrm{mm}^{3}\right)$ & $199 \pm 77$ & $179 \pm 53$ & .19 \\
\hline \multicolumn{4}{|l|}{ Operation performed (no. of patients) } \\
\hline Primary $\mathrm{CABG}^{*}$ & 1 & 4 & \\
\hline Reoperative CABG & 10 & 11 & \\
\hline Primary valve replacement, with or without $\mathrm{CABG}$ & 12 & 6 & \\
\hline Reoperative valve replacement, with or without CABG & 3 & 1 & \\
\hline Primary valve replacement, with or without other & 3 & 2 & \\
\hline CPB time (min) & $177 \pm 64$ & $155 \pm 69$ & .12 \\
\hline Lowest temperature during $\mathrm{CPB}\left({ }^{\circ} \mathrm{C}\right)$ & $31.3 \pm 3.9$ & $30.5 \pm 3.8$ & $>.2$ \\
\hline
\end{tabular}

Data are expressed as mean $\pm \mathrm{SD}$. $C A B G$, Coronary artery bypass grafting.

*Originally scheduled for coronary artery bypass grafting and valve replacement; during the operation a decision was made not to replace the valve.

Blood samples were withdrawn at the following time points: (1) immediately before heparin administration, (2) 5 minutes after heparin administration, (3) 40 minutes after the start of CPB, (4) after the administration of protamine and return of the ACT to prebypass levels (post-CPB), (5) $30 \mathrm{~min}$ utes after platelet transfusion, (6) 2 hours after platelet transfusion, (7) 4 hours after platelet transfusion, and (8) 24 hours after platelet transfusion. A standard template bleeding time was also performed at all the study times. ${ }^{20}$ Skin temperature at the site of the determination of the bleeding time was recorded with every bleeding time measurement. ${ }^{21} \mathrm{~A}$ volume of $0.6 \mathrm{~mL}$ blood shed from the template bleeding time site was aspirated and assayed for thromboxane $\mathrm{B}_{2}$, the stable metabolite of thromboxane $\mathrm{A}_{2}$; this is referred to henceforth as shed blood thromboxane $B_{2}$. The assay employed has been described previously elsewhere. ${ }^{21}$

Some of the hematologic measurements were made only in a portion of the total study population. These measurements and the numbers of randomly assigned patients in the 2 subgroups are as follows: shed blood thromboxane $\mathrm{B}_{2}, 21$ with cryopreserved platelets and 19 with liquid-preserved platelets; albumin, 9 with cryopreserved platelets and 11 with liquid-preserved platelets; fibrinogen, 10 with cryopreserved platelets and 14 with liquid-preserved platelets; fibronectin, 8 with cryopreserved platelets and 6 with liquid-preserved platelets; factor V, 7 with cryopreserved platelets and 11 with liquid-preserved platelets; factor VIII, 5 with cryopreserved platelets and 10 with liquid-preserved platelets; and D-dimer, 11 with cryopreserved platelets and 15 with liquid-preserved platelets.

Platelet function studies. Platelet aggregation in response to arachidonic acid (AA) and adenosine diphosphate (ADP), thromboxane $\mathrm{B}_{2}$ levels, platelet recovery from hypotonic stress, plasma $\mathrm{pH}$, and procoagulant activity were measured in the various types of platelets administered in accordance with the methods summarized in the Appendix.

Statistical analysis. Differences between the 2 groups in the preoperative patient characteristics, the baseline hematologic parameters, and the postoperative clinical events were assessed by the Student $t$ test for continuous variables and the $\chi^{2}$ test for dichotomous variables. The effects of platelet transfusion on the parameters assayed at 30 minutes, and at 2, 4, and 24 hours after transfusion were assessed by a 2-way repeated measures analysis of variance. In the case of platelet increment, platelet survival, shed blood thromboxane $\mathrm{B}_{2}$, and $\mathrm{D}$-dimer, a nonparametric repeated measures analysis of variance with treatment and time as factors (Friedman's method) was used. A $P$ value was calculated for an overall difference through time between the 2 patient groups. The Wilcoxon rank test was used to assess differences in blood loss between the groups.

\section{Results}

Seventy-three patients were entered into the study and randomly assigned to receive either liquid-preserved or cryopreserved platelets. Twenty patients were excluded from the study after random assignment. The reasons for exclusion were as follows: 6 patients had minimal diffuse oozing after protamine administration and were deemed by the surgeon not to require platelet transfusions, 6 patients had a documented site of surgical bleeding after the administration of protamine (3 received cryopreserved platelets and 3 received liquidpreserved platelets), and 5 patients (7\%) died within 24 hours after the institution of CPB for reasons not related to the platelet transfusions ( 3 received no platelets, 1 received cryopreserved platelets, and 1 received liquidpreserved platelets). Three patients ( 2 receiving cryopreserved platelets and 1 receiving liquid-preserved platelets) had $\varepsilon$-aminocaproic acid (Amicar) inadvertently administered during the immediate postoperative period. The mortality rate for all patients undergoing 
Table II. Comparison of characteristics of liquid-preserved pooled versus apheresed platelet transfusions

\begin{tabular}{lccc}
\hline & Pooled units & Apheresis units & P \\
\hline Age (d) & & & \\
Mean & $3.27 \pm 0.87$ & $3.43 \pm 1.17$ & \\
Median & 3.0 & 4.0 & \\
Range & $2-5$ & $346 \pm 166$ & .2 \\
Volume of platelets transfused per patient (mL) & $669 \pm 292$ & $5.19 \pm 2.3$ & .005 \\
No. of platelets transfused per patient $\left(10^{11}\right.$ cells) & $9.17 \pm 4.3$ & \\
\hline
\end{tabular}

Data are expressed as mean $\pm \mathrm{SD}$.

Table III. Comparison of characteristics of liquid-preserved versus cryopreserved platelet transfusions

\begin{tabular}{lccc}
\hline & Liquid-preserved & Cryopreserved & P \\
\hline Age (d) & & & \\
Mean & $3.4 \pm 1.1$ & $289 \pm 193$ & .0001 \\
Median & 3.8 & 250 & $30-720$ \\
Range & $2-5$ & $184 \pm 96$ & .0001 \\
Volume of platelets transfused/patient $(\mathrm{mL})$ & $487 \pm 278$ & $4.5 \pm 2.1$ & .008 \\
No. of platelets transfused per patient $\left(10^{11}\right.$ cells) & $6.9 \pm 3.9$ & & \\
\hline
\end{tabular}

Data are expressed as mean \pm SD.

cardiac operations during the study period was $3.8 \%$. Final data analysis was therefore performed on 53 patients, 24 of whom received cryopreserved platelets and 29 of whom received liquid-preserved platelets. In the group of 29 receiving the liquid-preserved platelets, 10 patients received 7 to 10 random donor platelet concentrates (pooled), 15 patients received apheresis platelets, and 4 patients received both random donor platelet concentrates and apheresis platelets.

Patient characteristics and outcomes. The preoperative patient characteristics are shown in Table I. All patients were men undergoing complex cardiac operations with prolonged crossclamp and CPB times. None of the patients had received aspirin or antiplatelet agents within 1 week before the operation. Patient characteristics and hematocrit, platelet count, bleeding time, prothrombin time, and partial thromboplastin time did not differ significantly between the 2 groups before CPB (Table I). Within the liquid-preserved patient group there were no significant differences in these parameters between those who received apheresed platelet transfusions and those who received pooled platelet transfusions. Four patients, 2 in each group, received an intraaortic balloon pump before operation. An additional 6 patients had an intra-aortic balloon pump placed either during the operation ( 2 in each group) or after the operation (1 in each group).

In both groups no clinical reactions were observed after the infusion of the platelets or other blood products. The incidences of thromboembolic complications and infections (wound infection, pneumonia) did not differ statistically between the 2 groups. The duration of tracheal intubation was significantly $(P=.04)$ longer in the patients who received the liquid-preserved platelets than in the patients who received the cryopreserved platelet transfusions $(31.7 \pm 25.4$ and $23.2 \pm 15.6$ hours, respectively).

Characteristics and hematologic effects of transfused platelets. The characteristics of the platelet transfusions in the liquid-preserved group are shown in Table II. The liquid-preserved apheresed platelets were transfused in smaller numbers and in lesser volumes. The characteristics of the transfused platelets used in the 2 patient groups are shown in Table III. The storage time before transfusion for cryopreserved platelets was $289 \pm$ 193 days, compared with $3.4 \pm 1.1$ days for liquid-preserved platelets $(P<.0001)$. More than $50 \%$ of the liquid-preserved platelet transfusions were stored for 4 to 5 days before administration (Fig 1). The duration of storage was not different between the liquid-preserved pooled platelets and the liquid-preserved apheresed platelets. The shortest period of cryopreservation was 30 days and the longest was 2 years (Fig 1). A significantly higher number of platelets was administered with the liquid-preserved transfusions than with the cryopreserved transfusions (Table III).

Table IV lists the values of the hematologic parameters measured in the 2 patient groups before CPB and at designated time points after the complete administration of the platelets. There were no differences before CPB between the 2 groups in any of the variables listed in Table IV. The hematocrit during the first 
Table IV. In vivo effects of transfused platelets

\begin{tabular}{|c|c|c|c|c|c|c|c|c|c|c|c|c|}
\hline & \multirow{2}{*}{\multicolumn{3}{|c|}{ Before $C P B$}} & \multicolumn{9}{|c|}{ After platelet transfusion } \\
\hline & & & & \multicolumn{2}{|l|}{$30 \mathrm{~min}$} & \multicolumn{2}{|l|}{$2 h$} & \multicolumn{2}{|l|}{$4 h$} & \multicolumn{2}{|l|}{$24 h$} & \multirow[b]{2}{*}{$\mathrm{P}^{\dagger}$} \\
\hline & Mean $\pm S D$ & $n$ & $\mathrm{P}^{*}$ & Mean $\pm S D$ & $n$ & Mean $\pm S D$ & $n$ & Mean $\pm S D$ & $n$ & Mean $\pm S D$ & $n$ & \\
\hline Hematocrit (\%) & & & $>.2$ & & & & & & & & & .027 \\
\hline Liquid-preserved & $33.7 \pm 5.0$ & 28 & & $27.5 \pm 3.9$ & 22 & $29.5 \pm 4.0$ & 13 & $28.3 \pm 3.9$ & 13 & $29.2 \pm 3.4$ & 12 & \\
\hline Cryopreserved & $34.8 \pm 4.8$ & 24 & & $31.7 \pm 6.3$ & 21 & $34.2 \pm 5.5$ & 24 & $31.7 \pm 5.2$ & 24 & $28.8 \pm 3.8$ & 23 & \\
\hline Platelet count $\left(10^{6}\right.$ cells $\left./ \mathrm{mL}\right)$ & & & $>.2$ & & & & & & & & & $>.2$ \\
\hline Liquid-preserved & $199 \pm 77$ & 27 & & $162 \pm 62$ & 26 & $152 \pm 61$ & 29 & $150 \pm 56$ & 29 & $138 \pm 52$ & 24 & \\
\hline Cryopreserved & $179 \pm 53$ & 23 & & $122 \pm 33$ & 21 & $127 \pm 41$ & 24 & $124 \pm 42$ & 23 & $155 \pm 207$ & 23 & \\
\hline Mean platelet volume $\left(\mu \mathrm{m}^{3}\right)$ & & & $>.2$ & & & & & & & & & $>.2$ \\
\hline Liquid-preserved & $9.5 \pm 1.4$ & 21 & & $8.9 \pm 1.1$ & 21 & $9.3 \pm 1.1$ & 21 & $9.5 \pm 1.4$ & 21 & $9.3 \pm 0.9$ & 17 & \\
\hline Cryopreserved & $9.2 \pm 0.9$ & 19 & & $8.9 \pm 1.2$ & 17 & $9.0 \pm 1.0$ & 19 & $9.1 \pm 0.9$ & 19 & $9.2 \pm 1.0$ & 18 & \\
\hline Platelet increment $\left(10^{8}\right.$ cells $)$ & & & & & & & & & & & & $.021 \ddagger$ \\
\hline Liquid-preserved & & & & $2.5 \pm 2.2$ & 24 & $2.3 \pm 2.3$ & 27 & $2.2 \pm 2.2$ & 27 & $1.8 \pm 1.6$ & 22 & \\
\hline Cryopreserved & & & & $0.8 \pm 1.1$ & 20 & $1.3 \pm 1.4$ & 24 & $0.9 \pm 1.3$ & 24 & $0.7 \pm 1.2$ & 24 & \\
\hline Platelet survival (\%) & & & & & & & & & & & & $.071 \ddagger$ \\
\hline Liquid-preserved & & & & $36.8 \pm 26.0$ & 21 & $37.2 \pm 35.4$ & 26 & $33.5 \pm 31.7$ & 26 & $30.6 \pm 29.8$ & 22 & \\
\hline Cryopreserved & & & & $16.9 \pm 22.7$ & 19 & $23.6 \pm 27.8$ & 22 & $21.8 \pm 28.7$ & 23 & $13.4 \pm 19.1$ & 24 & \\
\hline Bleeding time (min) & & & $>.2$ & & & & & & & & & $>.2$ \\
\hline Liquid-preserved & $6.8 \pm 2.8$ & 27 & & $10.8 \pm 4.1$ & 25 & $10.9 \pm 4.1$ & 28 & $10.0 \pm 4.4$ & 28 & $7.4 \pm 2.6$ & 23 & \\
\hline Cryopreserved & $6.9 \pm 3.2$ & 23 & & $10.7 \pm 3.2$ & 21 & $10.3 \pm 4.1$ & 22 & $9.5 \pm 3.7$ & 23 & $7.7 \pm 3.5$ & 22 & \\
\hline Skin temp at bleeding time site $\left({ }^{\circ} \mathrm{C}\right)$ & & & $>.2$ & & & & & & & & & $>.2$ \\
\hline Liquid-preserved & $29.4 \pm 1.2$ & 27 & & $30.2 \pm 1.8$ & 28 & $30.1 \pm 1.8$ & 28 & $30.6 \pm 1.7$ & 29 & $31.7 \pm 2.0$ & 23 & \\
\hline Cryopreserved & $29.3 \pm 1.8$ & 23 & & $30.3 \pm 2.1$ & 22 & $30.1 \pm 2.0$ & 23 & $30.5 \pm 2.9$ & 22 & $30.7 \pm 1.8$ & 20 & \\
\hline Shed blood $\mathrm{TXB}_{2}(\mathrm{pg} / 0.1 \mathrm{~mL})$ & & & $>.2$ & & & & & & & & & $.068 \div$ \\
\hline Liquid-preserved & $825 \pm 840$ & 11 & & $319 \pm 237$ & 11 & $330 \pm 234$ & 12 & $397 \pm 385$ & 13 & $647 \pm 621$ & 12 & \\
\hline Cryopreserved & $996 \pm 719$ & 14 & & $654 \pm 859$ & 13 & $440 \pm 245$ & 15 & $612 \pm 464$ & 15 & $1080 \pm 1147$ & 11 & \\
\hline Plasma fibrinogen (mg/dL) & & & .13 & & & & & & & & & .024 \\
\hline Liquid-preserved & $333 \pm 99$ & 13 & & $191 \pm 35$ & 9 & $192 \pm 44$ & 11 & $187 \pm 46$ & 11 & $321 \pm 84$ & 7 & \\
\hline Cryopreserved & $416 \pm 166$ & 8 & & $262 \pm 86$ & 7 & $291 \pm 110$ & 8 & $290 \pm 105$ & 8 & $427 \pm 126$ & 9 & \\
\hline Serum albumin $(\mathrm{g} / \mathrm{dL})$ & & & $>.2$ & & & & & & & & & $>.2$ \\
\hline Liquid-preserved & $3.26 \pm 0.43$ & 11 & & $2.49 \pm 0.46$ & 9 & $2.79 \pm 0.53$ & 10 & $2.73 \pm 0.59$ & 10 & $2.87 \pm 0.66$ & 9 & \\
\hline Cryopreserved & $3.15 \pm 0.30$ & 8 & & $2.58 \pm 0.63$ & 9 & $3.09 \pm 0.61$ & 10 & $3.26 \pm 0.77$ & 10 & $3.14 \pm 0.54$ & 9 & \\
\hline Factor $\mathrm{V}$ in plasma $(\%)$ & & & $>.2$ & & & & & & & & & .166 \\
\hline Liquid-preserved & $67.5 \pm 19.1$ & 10 & & $22.4 \pm 6.9$ & 10 & $22.9 \pm 4.0$ & 11 & $28.2 \pm 8.5$ & 10 & $42.3 \pm 15.5$ & 10 & \\
\hline Cryopreserved & $72.6 \pm 21.4$ & 7 & & $25.7 \pm 15.1$ & 6 & $26.1 \pm 12.1$ & 8 & $30.7 \pm 10.0$ & 8 & $69.0 \pm 32.2$ & 7 & \\
\hline Factor VIII in plasma (\%) & & & .15 & & & & & & & & & .125 \\
\hline Liquid-preserved & $115 \pm 36$ & 11 & & $54 \pm 23$ & 10 & $59 \pm 24$ & 12 & $63 \pm 25$ & 11 & $118 \pm 56$ & 9 & \\
\hline Cryopreserved & $128 \pm 12$ & 7 & & $64 \pm 26$ & 7 & $77 \pm 28$ & 8 & $93 \pm 46$ & 8 & $168 \pm 87$ & 8 & \\
\hline Plasma fibronectin $(\mu \mathrm{g} / \mathrm{dL})$ & & & $>.2$ & & & & & & & & & $>.2$ \\
\hline Liquid-preserved & $384 \pm 162$ & 9 & & $234 \pm 88$ & 8 & $223 \pm 85$ & 10 & $204 \pm 92$ & 10 & $196 \pm 57$ & 9 & \\
\hline Cryopreserved & $342 \pm 74$ & 10 & & $228 \pm 51$ & 8 & $236 \pm 57$ & 10 & $221 \pm 44$ & 10 & $221 \pm 44$ & 10 & \\
\hline Plasma D-dimer $(\mu \mathrm{g} / \mathrm{dL})$ & & & $>.2$ & & & & & & & & & $>.2 \ddagger$ \\
\hline Liquid-preserved & $616 \pm 282$ & 12 & & $2602 \pm 1449$ & 11 & $3333 \pm 1203$ & 12 & $4565 \pm 4155$ & 12 & $3381 \pm 2176$ & 8 & \\
\hline Cryopreserved & $1011 \pm 1258$ & 8 & & $3311 \pm 1942$ & 9 & $4320 \pm 2225$ & 10 & $6928 \pm 4967$ & 10 & $1647 \pm 548$ & 7 & \\
\hline
\end{tabular}

temp, Temperature.

* Significance of $t$ test between the 2 groups at baseline.

$\dagger$ Significance between the 2 groups by repeated measures parametric analysis of variance (30 minutes and 2, 4, and 24 hours).

$\ddagger$ Significance between the groups by nonparametric analysis of variance (Friedman test).

4 hours after transfusion was significantly higher in the patients receiving the cryopreserved platelets. The platelet count and the mean platelet volume were not significantly different between the 2 patient groups, but the platelet increment after transfusion was significantly lower in the patients receiving the cryopreserved platelet transfusions than in those receiving the liquid- preserved platelet transfusions. The decrease in platelet increment was associated with an indeterminate decrease in platelet survival in the cryopreserved platelet group $(P=.071)$. This latter decrease might have achieved statistical significance with a larger patient cohort. The postoperative bleeding times and skin temperature at the site of the bleeding time deter- 


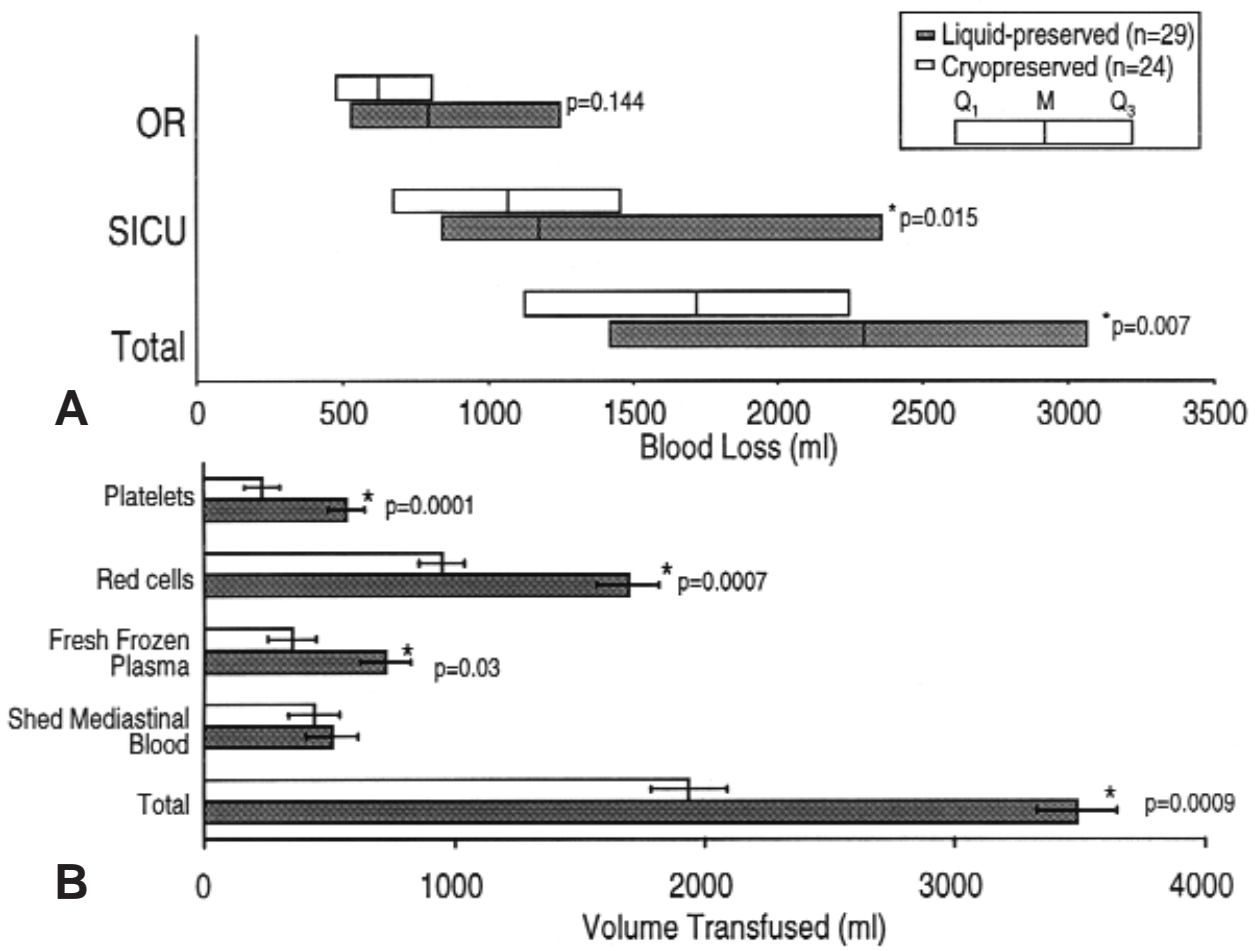

Fig 2. A, Blood loss measured in the operating room $(O R)$, blood loss measured in the surgical intensive care unit (SICU), and combined total blood loss in patients who received liquid-preserved platelet transfusions and in those who received cryopreserved platelet transfusions. Data are shown as median and IQR. $M$, Median; $Q 1$, 25th percentile; $Q 3$, 75th percentile. B, Volumes of transfused blood products received by the same groups. Data are shown as mean \pm SEM.

Table V. In vivo effects of transfused liquid-preserved platelets

\begin{tabular}{|c|c|c|c|c|c|c|c|c|c|c|c|c|}
\hline & \multirow{2}{*}{\multicolumn{3}{|c|}{ Before $C P B$}} & \multicolumn{9}{|c|}{ After platelet transfusion } \\
\hline & & & & \multicolumn{2}{|l|}{$30 \mathrm{~min}$} & \multicolumn{2}{|l|}{$2 h$} & \multicolumn{2}{|l|}{$4 h$} & \multicolumn{2}{|l|}{$24 h$} & \multirow[b]{2}{*}{$\mathrm{P} \dagger$} \\
\hline & Mean $\pm S D$ & $n$ & $\mathrm{P}^{*}$ & Mean $\pm S D$ & $n$ & Mean $\pm S D$ & $n$ & Mean $\pm S D$ & $n$ & Mean $\pm S D$ & $n$ & \\
\hline Hematocrit (\%) & & & $>.2$ & & & & & & & & & $>.2$ \\
\hline Pooled & $33.7 \pm 4.2$ & 10 & & $27.1 \pm 3.3$ & 9 & $29.6 \pm 4.9$ & 6 & $26.2 \pm 3.3$ & 6 & $29.6 \pm 2.5$ & 5 & \\
\hline Apheresis & $33.3 \pm 5.3$ & 14 & & $28.8 \pm 3.7$ & 14 & $30.1 \pm 1.4$ & 4 & $29.3 \pm 2.6$ & 4 & $28.6 \pm 2.1$ & 4 & \\
\hline Platelet count $\left(10^{6}\right.$ cells $\left./ \mathrm{mL}\right)$ & & & $>.2$ & & & & & & & & & $>.2$ \\
\hline Pooled & $191 \pm 66$ & 10 & & $196 \pm 62$ & 9 & $180 \pm 62$ & 10 & $180 \pm 67$ & 10 & $167 \pm 37$ & 9 & \\
\hline Apheresis & $197 \pm 73$ & 13 & & $150 \pm 61$ & 14 & $142 \pm 61$ & 15 & $136 \pm 49$ & 15 & $127 \pm 53$ & 11 & \\
\hline Mean platelet volume $\left(\mu \mathrm{m}^{3}\right)$ & & & $>.2$ & & & & & & & & & $>.2$ \\
\hline Pooled & $9.2 \pm 1.1$ & 7 & & $8.7 \pm 0.8$ & 8 & $9.3 \pm 1.0$ & 8 & $9.3 \pm 0.9$ & 8 & $9.2 \pm 0.9$ & 8 & \\
\hline Apheresis & $9.6 \pm 1.7$ & 11 & & $9.2 \pm 1.3$ & 11 & $9.5 \pm 1.2$ & 10 & $9.7 \pm 1.8$ & 10 & $9.4 \pm 1.0$ & 6 & \\
\hline Platelet increment $\left(10^{8}\right.$ cells) & & & & & & & & & & & & $>.2$ \\
\hline Pooled & & & & $3.8 \pm 2.3$ & 8 & $3.3 \pm 2.7$ & 10 & $3.4 \pm 2.7$ & 9 & $2.2 \pm 1.8$ & 8 & \\
\hline Apheresis & & & & $2.2 \pm 1.8$ & 14 & $1.9 \pm 1.9$ & 15 & $1.6 \pm 1.4$ & 15 & $1.7 \pm 1.6$ & 12 & \\
\hline Platelet survival (\%) & & & & & & & & & & & & $>.2$ \\
\hline Pooled & & & & $34.2 \pm 16.3$ & 7 & $38.7 \pm 34.2$ & 10 & $39.2 \pm 35.5$ & 9 & $33.7 \pm 30.6$ & 8 & \\
\hline Apheresis & & & & $44.5 \pm 27.3$ & 12 & $40.5 \pm 36.8$ & 14 & $33.1 \pm 29.0$ & 14 & $33.0 \pm 30.1$ & 11 & \\
\hline
\end{tabular}

*Significance of $t$ test between the 2 groups at baseline.

$\dagger$ Significance by analysis of variance between the 2 groups at multiple time points (30 minutes and 2, 4, and 24 hours). 


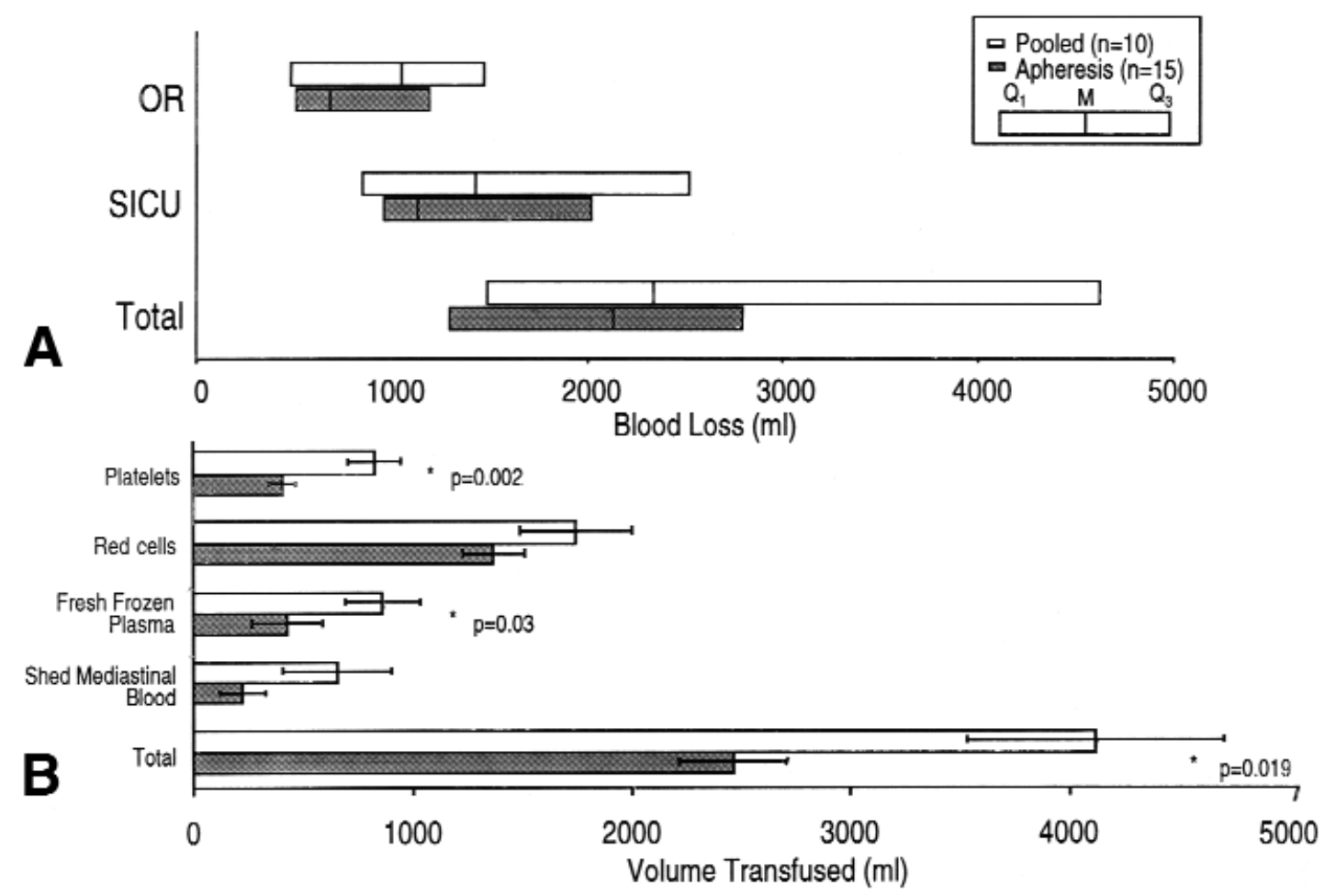

Fig 3. A, Blood loss measured in the operating room $(O R)$, blood loss measured in the surgical intensive care unit $(S I C U)$, and combined total blood loss in patients who received liquid-preserved pooled platelet transfusions and in those who received liquid-preserved apheresed platelet transfusions. Data are shown as median and IQR. $M$, Median; $Q 1$, 25th percentile; $Q 3$, 75th percentile. B, Volumes of transfused blood products received by the same groups. Data are shown as mean \pm SEM.

mination were not significantly different between the groups. After platelet transfusion, the concentration of thromboxane $\mathrm{B}_{2}$ in the blood shed at the site of the bleeding time determination was indeterminately higher in the patients receiving the cryopreserved platelets $(P=.068)$, and this also might have reached statistical significance with a larger patient cohort (Table IV).

After platelet transfusion, plasma fibrinogen level was significantly higher in the patients receiving the cryopreserved platelets than in the patients receiving the liquid-preserved platelets (Table IV). Serum albumin, plasma factors V and VIII, and plasma fibronectin and D-dimer were not significantly different in the 2 patient groups (Table IV).

Table V demonstrates that no differences were noted in the hematocrit, platelet count, mean platelet volume, platelet increment, platelet survival, and bleeding time according to whether pooled or apheresed platelets were transfused.

Blood loss and transfusion requirements. The intraoperative blood loss recorded after the administration of protamine accounted for $30 \%$ and $29 \%$ of the total blood loss in the patient groups receiving liquidpreserved and cryopreserved platelet transfusions, respectively (Fig 2). Blood loss after heparin reversal with protamine was lower in patients transfused with cryopreserved platelets than in patients transfused with liquid-preserved platelets (Fig 2,A). The median total blood loss in the patients receiving the cryopreserved platelet transfusions was $1721 \mathrm{~mL}$, with an interquartile range (IQR) of $1118 \mathrm{~mL}$. In the patients receiving the liquid-preserved platelet transfusions, the median total blood loss was $2298 \mathrm{~mL}$ and the IQR was 1639 $\mathrm{mL}(P=.007)$. Because the total surgical intensive care unit blood loss could be contaminated by serous, nonsanguineous drainage from the chest, an analysis was performed in which the blood loss during only the first 8 hours after protamine administration was analyzed (not shown in Fig 2, A). There again was significantly less total blood loss in the patients receiving cryopreserved platelets (median $1093 \mathrm{~mL}$, IQR $566 \mathrm{~mL}$, vs $1443 \mathrm{~mL}, \mathrm{IQR} 1251 \mathrm{~mL}$, in the patients receiving liquid preserved platelets, $P=.05$ ). Blood loss did not differ according to whether the patient received liquid- 


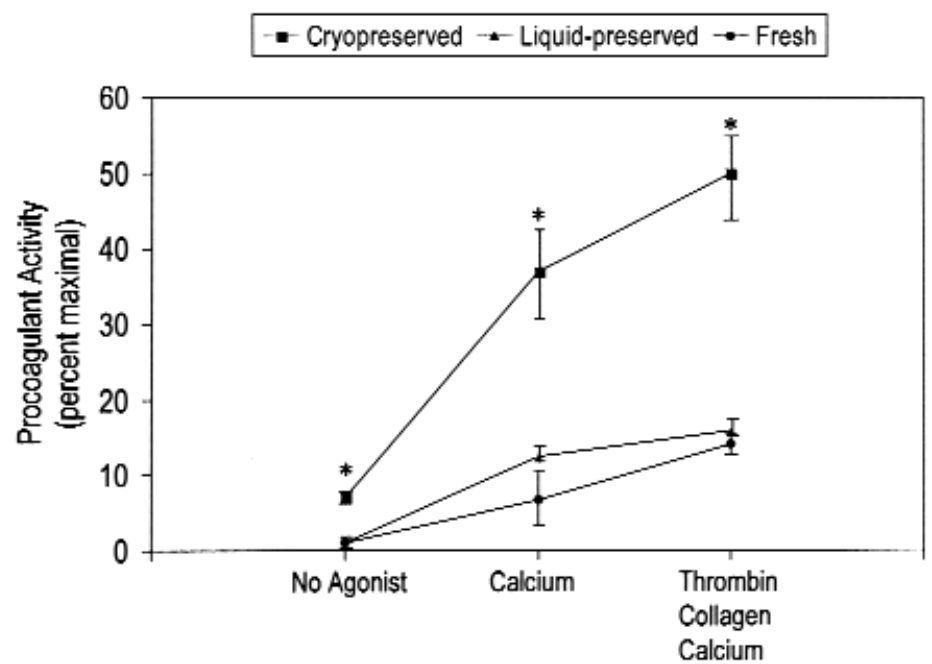

Fig 4. In vitro procoagulant activities of fresh, liquid-preserved, and cryopreserved platelets. Liquid-preserved platelets were stored in the blood bank for 3 to 4 days before assay. Procoagulant activity was determined by flow cytometric analysis of the binding of the activated coagulation factor $\mathrm{V}$-specific monoclonal antibody V237. Platelets were stimulated $\left(10\right.$ minutes at $\left.37^{\circ} \mathrm{C}\right)$ either with thrombin $(2 \mathrm{U} / \mathrm{mL})$, collagen $(20 \mu \mathrm{g} / \mathrm{mL})$, and calcium chloride $(3 \mathrm{mmol} / \mathrm{L})$; with calcium chloride $(3 \mathrm{mmol} / \mathrm{L})$; or with buffer alone (No Agonist). Values were expressed as the percentage of maximal V237 binding, as determined by the effect on fresh platelets of the calcium ionophore A23187 $(40 \mu \mathrm{mol} / \mathrm{L})$ and calcium chloride $(3 \mathrm{mmol} / \mathrm{L})$. Data are shown as mean \pm SEM. Asterisk indicates $P<.05$ for comparison between cryopreserved platelets and fresh platelets stimulated with the same agonist. Comparisons between liquid-preserved platelets and fresh platelets were not significantly different.

Table VI. Results of in vitro platelet function studies

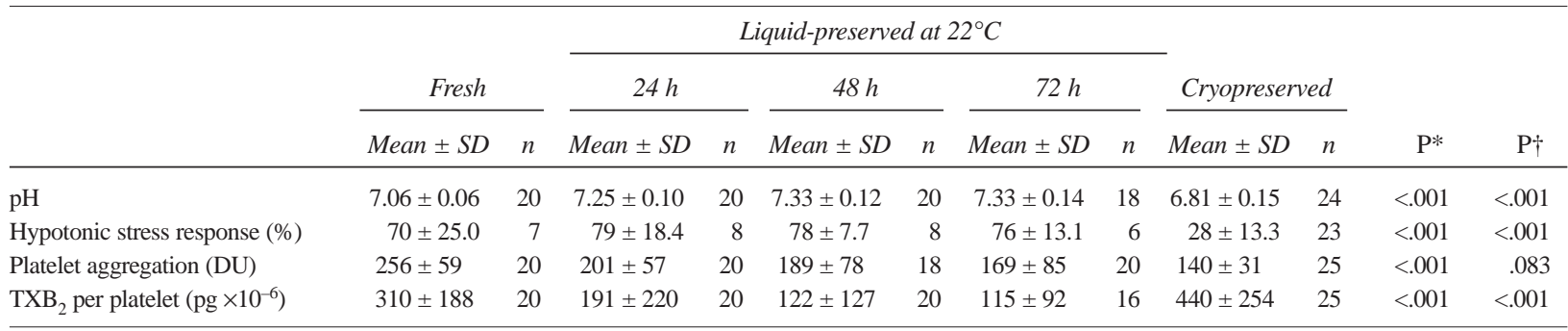

Liquid-preserved platelets were all apheresis units. $T X B_{2}$, Thromboxane $\mathrm{B}_{2} ; D U$, digitizer units.

*By analysis of variance.

$\dagger$ Difference between 72-hour liquid-preserved and cryopreserved platelets, by $t$ test.

preserved apheresed or liquid-preserved pooled platelets (Fig 3, A).

To ensure that the increase in blood loss observed in the patients who received the liquid-preserved platelet transfusions was not due to the higher number of patients undergoing valve replacement (with or without coronary artery bypass grafting) in this group (12 vs 6 patients in the cryopreserved group), the analyses were repeated after exclusion from the liquid-preserved group of the 6 patients who had the longest duration of $\mathrm{CPB}$. The average duration of $\mathrm{CPB}$ in the resultant 23 patients receiving liquid-preserved platelet transfusions was $161 \pm 57$ minutes. This was not significantly different $(P=.4)$ from the average CPB duration of $159 \pm$ 69 minutes in the 23 patients receiving cryopreserved platelet transfusions. The blood loss, however, remained significantly higher in the patients receiving the liquid-preserved platelet transfusions (total median blood loss in the latter $2329 \mathrm{~mL}$, IQR $1715 \mathrm{~mL}$, vs $1830 \mathrm{~mL}$, IQR $979 \mathrm{~mL}$, in the patients receiving cryopreserved platelet transfusions, $P=.0089$ ).

The volume of blood products used was lower in 
patients transfused with cryopreserved platelets than in patients transfused with liquid-preserved platelets (Fig $2, B)$. The analysis of the blood products transfused was also repeated after exclusion of the 6 patients undergoing valve replacement in the liquid-preserved group who had the longest duration of CPB. The mean \pm SD of the total volume of blood products transfused (not shown in Fig 2) continued to be significantly higher in the patients who received the liquid-preserved platelet transfusions than in those who received the cryopreserved platelet transfusions $(3426 \pm 1963 \mathrm{~mL}$ vs 1933 $\pm 1042 \mathrm{~mL}, P=.0012$ ). Fig $3, B$, also shows that patients transfused with liquid-preserved pooled platelets received more platelets, fresh-frozen plasma, and total blood products than did the patients who were transfused with liquid-preserved apheresed platelets.

These statistical analyses of blood loss and transfusion requirements were repeated without the exclusion of any patient (analysis by intent to treat). Statistically significant differences continued to be observed between the 2 types of platelet transfusion. Log transformation of the data resulted in $P=.04$ for the difference in blood loss between the 2 groups and $P=.008$ for the difference in blood product transfusion between the 2 groups.

In vitro function of fresh, liquid-preserved, and cryopreserved platelets (Table VI). The in vitro studies were performed on platelets obtained from healthy volunteers. The $\mathrm{pH}$ of cryopreserved platelets was significantly lower $(P<.0001)$ than the $\mathrm{pH}$ of fresh platelets; this in turn was significantly lower $(P<$ .0001) than the $\mathrm{pH}$ of the liquid-preserved platelets. Likewise, the response to hypotonic stress was markedly lower in the cryopreserved platelets than in either the fresh $(P=.003)$ or the liquid-preserved platelets $(P<$ .0001). Platelet aggregation after cryopreservation was reduced with respect to that of the fresh platelets $(P<$ $.0001)$; it was not significantly different from platelet aggregation after 72 hours of liquid preservation.

In contrast, stimulation of cryopreserved platelets with AA and ADP resulted in plasma levels of thromboxane $B_{2}$ that were significantly higher than those in platelets stimulated after 72-hours of liquid preservation $(P<.001)$. In addition, cryopreserved platelets had more surface procoagulant activity than either liquidpreserved platelets stored at $22^{\circ} \mathrm{C}$ for 3 to 4 days or fresh platelets (Fig 4): $6.6 \% \pm 2.7 \%$ of maximum for cryopreserved platelets versus $0.9 \% \pm 0.5 \%$ of maximum for liquid-preserved platelets versus $0.7 \% \pm 0.3 \%$ of maximum for fresh platelets. Stimulation of the platelets either with a combination of thrombin, collagen, and calcium chloride or with calcium chloride alone also resulted in significantly greater procoagulant activity on the surfaces of the cryopreserved platelets than on the surfaces of the liquid-preserved platelets (Fig 4).

\section{Discussion}

Bleeding during and after cardiac operations is related to 2 causes: (1) the surgical incision that cuts into blood vessels and vascularized tissues (surgical bleeding) and (2) defects in hemostasis that prevent normal clotting and that are amplified by the conditions of CPB. ${ }^{2,3}$ This latter type of bleeding can be considered nonsurgical because it does not originate from a specific anatomic incision or tear. Properly quantified, nonsurgical blood loss has been used as a clinical tool for the assessment of the hemostatic efficacy of pharmacologic interventions. ${ }^{12,22}$ In this prospective randomized study, a specific effort was made to quantify nonsurgical blood loss. In contrast to most other studies, which only measured the blood lost through the chest tubes in the surgical intensive care unit, the measurement of blood loss in this study was started in the operating room after complete reversal with protamine of the effects of heparin. During the ensuing period of chest closure, all the blood oozing from the tissues, including the blood contained in the sponges, was collected and accurately measured by a trained research assistant. Surgical mishaps occurring during this period and resulting in excessive surgical blood loss were prospectively identified, and affected patients were excluded from analysis. Patients brought back to the operating room for control of excessive postoperative bleeding were also excluded.

The nonsurgical blood loss was significantly lower in the patients receiving the cryopreserved platelets than in the patients receiving the liquid-preserved platelets (Fig 2,A), although the risk profiles of the 2 groups were similar. This difference was accompanied by a significant, if transient, increase in the postoperative hematocrit in the former group (Table IV) and by a significant reduction in the amount of blood products transfused (Fig 2, B).

The reduction in the postoperative blood loss seen in the patients receiving cryopreserved platelet transfusions probably reflects better in vivo hemostatic function of the cryopreserved platelets compared to the liquid-preserved platelets. Nonsurgical blood loss after CPB has been recognized as a good indicator of hemostatic function in the comparative assessment of the efficacy of hemostatic drugs in patients undergoing cardiac operations. ${ }^{22}$ Furthermore, although the postoperative bleeding times were not different in the 2 patient groups in this study, the level of thromboxane $\mathrm{B}_{2}$ in the blood shed at the bleeding time determination 
site was higher in the patients receiving the cryopreserved platelets than in those receiving the liquid-preserved platelet transfusions. This difference approached but did not reach statistical significance because of the relatively small sample size in which this measurement was performed. An increased ability of platelets to generate thromboxane at the bleeding time site has been shown to be a reliable measure of the platelets' in vivo hemostatic effect. ${ }^{21,23}$

This study was not designed to investigate the effects of liquid-preserved pooled and those of liquid-preserved apheresed platelet transfusions separately because the administration of these liquid-preserved platelet transfusions was predicated on the availability of either type in the blood bank. When the results for these 2 types of liquid-preserved platelet transfusions were analyzed separately, however, patients who received the liquid-preserved pooled platelet transfusions were found to have required a significantly higher volume of blood products after the operation than did patients who received liquid-preserved apheresed platelets (Fig 3, B). This was due in part to the higher volumes transfused with the pooled platelets. There was also a tendency for the blood loss to be higher in the patients who received the liquid-preserved pooled platelet transfusions (Fig 3, A). The small sample size and poor statistical power, however, precluded this study from making a definitive statement about the merits of liquid-preserved pooled platelets versus liquid-preserved apheresed platelets.

In this study decreased blood loss was demonstrated in the patients receiving cryopreserved platelets despite the facts that smaller numbers of cryopreserved platelets had been transfused (Table II) and the posttransfusion platelet increment was decreased in the patients receiving cryopreserved platelet transfusions (Table IV). The decrease in platelet survival that was observed in the patients receiving the cryopreserved platelets approached statistical significance and corroborated previous studies demonstrating inferior platelet survival with cryopreservation. ${ }^{24,25}$ These findings confirmed in the setting of CPB data from a previous study of healthy volunteers receiving aspirin that indicated that the in vivo hemostatic effect of transfused platelets did not correlate with their survival in the circulation. ${ }^{10}$ It is clear from this study that the decreased in vivo survival did not interfere with the ability of the cryopreserved platelets to reduce blood loss after CPB.

Compared with standard liquid-preserved platelets, cryopreserved platelets have been reported to have reductions in function in vitro, including adhesive capacity ${ }^{8}$ stimulus-response coupling, ${ }^{7}$ aggregation, ${ }^{5,7}$ and granule release. ${ }^{5,6}$ They have also been found to have lower $\mathrm{pH}$ levels ${ }^{25}$ and more morphologic abnormalities. This study also showed an adverse effect of cryopreservation on in vitro quality of the platelets, as assessed by 3 commonly used tests. Platelet aggregation in response to AA and ADP was lower in the cryopreserved platelets than in the liquid-preserved platelets. The $\mathrm{pH}$ of the milieu of the cryopreserved platelets was lower than that of the liquid-preserved platelets, and the recovery from hypotonic stress, which has been shown to correlate with in vivo platelet recovery, ${ }^{26}$ was also less in the cryopreserved than the liquid-preserved platelets. These in vitro tests did not correlate with the superior in vivo effect of the cryopreserved platelets that was shown by their ability to reduce blood loss after CPB.

This study also assessed the thromboxane production and the procoagulant activities of liquid-preserved and cryopreserved platelets, and the results of these in vitro tests did correlate with in vivo hemostatic function. Cryopreserved platelets generated more surface procoagulant activity than did liquid-preserved platelets. Formation of a procoagulant surface for the assembly of the coagulation system is an important function of platelets in the hemostatic process. ${ }^{27}$ Cryopreserved platelets also generated more thromboxane than did liquid-preserved platelets. Thromboxane $\mathrm{A}_{2}$, a metabolic product of AA, causes vasoconstriction and platelet aggregation. ${ }^{28}$ Through these mechanisms, the additional generation of thromboxane by cryopreserved platelets is likely to have reduced blood loss from the site of injury. Additional studies are needed to determine the mechanisms through which cryopreservation of platelets increases in vitro procoagulant activity and thromboxane production and improves in vivo hemostatic function.

In our study, patients receiving the cryopreserved platelet transfusions had a significantly shorter duration of postoperative intubation. This difference could not be explained by variables measured in this study. Possibly the shorter intubation reflects an improvement in pulmonary vascular permeability related to a salutary effect of cryopreserved platelets on endothelial integrity. Johnson and associates ${ }^{29}$ have reported that maintenance of endothelial integrity is among the functions of platelets.

This study shows the following: (1) Cryopreserved platelet transfusions are superior to liquid-preserved platelets in reducing nonsurgical blood loss and the need for blood product transfusions after CPB. (2) The reduction in nonsurgical blood loss seen in the patients receiving cryopreserved platelet transfusions probably reflects improved in vivo hemostatic function of cryopreserved platelets after CPB. (3) Some in vitro measures of platelet 
quality (aggregation, $\mathrm{pH}$, hypotonic stress) may not reflect the in vivo quality of platelet transfusions after $\mathrm{CPB}$, whereas other in vitro measures (platelet procoagulant activity and thromboxane) do reflect this.

We greatly appreciate the efforts and advice of Dr Michael Crittenden. We also acknowledge Mheir Doursounian, Michael Zolkewitz, Gina Ragno, Maria Hansson-Wicher, and Stephanie McCarter in the completion of this study.

\section{REFERENCES}

1. Khuri SF, Wolfe J, Josa M, Axford TC, Szymanski I, Assousa S, et al. Hematologic changes during and after cardiopulmonary bypass and their relationship to the bleeding time and nonsurgical blood loss. J Thorac Cardiovasc Surg 1992;104:94-107.

2. Khuri SF, Michelson AD, Valeri CR. Effects of cardiopulmonary bypass on hemostasis. In: Loscalzo J, Schafer AI, editors. Thrombosis and hemorrhage. Cambridge [MA]: Blackwell; 1994. p. 1051-73.

3. Kestin AS, Valeri CR, Khuri SF, Loscalzo J, Ellis PA, MacGregor $\mathrm{H}$, et al. The platelet function defect of cardiopulmonary bypass. Blood 1993;82:107-17.

4. Murphy S, Rebulla P, Bertolini F, Holme S, Moroff G, Snyder E, et al. In vitro assessment of the quality of stored platelet concentrates. Trans Med Rev 1994;8:29-36.

5. Spector JI, Skrabut EM, Valeri CR. Oxygen consumption, platelet aggregation, and release reactions in platelets freeze-preserved with dimethysulfoxide. Transfusion 1977;17:99-109.

6. Melaragno AJ, Carciero R, Feingold H, Talarico L, Weintraub L, Valeri CR. Cryopreservation of human platelets using $6 \%$ dimethylsulfoxide and storage at $-80^{\circ} \mathrm{C}$ : effects of 2 years of frozen storage at $-80^{\circ} \mathrm{C}$ and transportation in dry ice. Vox Sang 1985;49:245-58.

7. Dullemond-Westland AC, van Prooijen HC, Riemens MI, Akkerman JW. Cryopreservation disturbs stimulus-response coupling in a platelet subpopulation. Br J Haematol 1987;67:325-33.

8. Owens M, Cimino C, Donnelly J. Cryopreserved platelets have decreased adhesive capacity. Transfusion 1991;31:160-3.

9. Shepherd KM, Sage RE, Barber S, O'Brien E. Platelet cryopreservation. In vitro aggregation studies. Cryobiology 1984;21: 39-43.

10. Valeri CR. Hemostatic effectiveness of liquid-preserved and previously frozen human platelets. N Engl J Med 1974;290:353-8.

11. Schiffer CA, Aisner J, Wiemik PH. Frozen autologous platelet transfusion for patients with leukemia. N Engl J Med 1978; 299:7-12.

12. Blauhut B, Gross C, Necek S, Doran JE, Spath P, LundsgaardHansen P. Effects of high-dose aprotinin on blood loss, platelet function, fibrinolysis, complement, and renal function after cardiopulmonary bypass. J Thorac Cardiovasc Surg 1991;101:958-67.

13. Van Slyke DD, Phillips RA, Dole VP, Hamilton PB, Archibald RM, Plazin J. Calculation of hemoglobin from blood specific gravities. J Biol Chem 1949:349-60.

14. Thompson CB, Eaton KA, Princiotta SM, Rushin CA, Valeri CR. Size dependent platelet subpopulations: relationship of platelet volume to ultrastructure, enzymatic activity, and function. $\mathrm{Br} \mathbf{J}$ Haematol 1982;50:509-19.

15. Feingold HM, Pivacek LE, Melaragno AJ, Valeri CR. Coagulation assays and platelet aggregation patterns in human, baboon, and canine blood. Am J Vet Res 1986;47:2197-9.
16. Saba TM, Albert WH, Blumenstock FA, Evanega G, Staehler F, Cho F. Evaluation of a rapid immunoturbidometric assay for opsonic fibronectin in surgical and trauma patients. J Lab Clin Med 1981;98:482-91.

17. Teien AN, Lie M, Abildgaard U. Assay of heparin in plasma using a chromogenic substrate for activated factor X. Thromb Res 1976;8:413-6.

18. Rylatt DB, Blake AS, Cottis LE, et al. An immunoassay for human D-dimer using monoclonal antibodies. Thromb Res 1983; 31:767-78.

19. Kingsley GR. Determination of serum total protein, albumin, and globulin by the Buiret reactions. J Biol Chem 1939;131:197-200.

20. Babson SR, Babson AL. Development and evaluation of a disposable device for performing simultaneous duplicate bleeding time determinations. Am J Clin Pathol 1978;70:406-8.

21. Valeri CR, MacGregor H, Cassidy G, Tinney R, Pompei F. Effects of temperature on bleeding time and clotting time in normal male and female volunteers. Crit Care Med 1995;23:698-704.

22. Mannucci PM. Hemostatic drugs. N Engl J Med 1998;339:24553.

23. Gerrard JM, Taback S, Singhroy S, et al. In vivo measurement of thromboxane $\mathrm{B}_{2}$ and 6-keto-prostaglandin $\mathrm{F}_{1} \alpha$ in humans in response to a standard vascular injury and the influence of aspirin. Circulation 1989;79:29-38.

24. Valeri CR. Preservation of red cells and platelets: freezing, storage, recovery, and quality. In: Harris JR, editor. Blood separation and plasma fractionation. New York: Wiley-Liss; 1991. p. 127-53.

25. Valeri CR. The current state of platelet and granulocyte cryopreservation. Crit Rev Clin Lab Sci 1981;14:21-74.

26. Valeri CR, Feingold H, Marchionni LD. The relation between response to hypotonic stress and the ${ }^{51} \mathrm{Cr}$ recovery in vivo of preserved platelets. Transfusion 1974;4:331-7.

27. Bevers EM, Comfurius P, Zwaal RF. Platelet procoagulant activity: physiological significance and mechanisms of exposure. Blood Rev 1991;5:146-54.

28. Fitzgerald GA. Mechanisms of platelet activation: thromboxane $\mathrm{A}_{2}$ as an amplifying signal for other agonists. Am J Cardiol 1991;68:11B-5B.

29. Johnson SA, Van Horn DL, Pederson HJ, Marr J. The function of platelets: a review. Transfusion 1966;6:3-17.

30. Michelson AD, Barnard MR, Hechtman HB, MacGregor H, Connolly RJ, Loscalzo J, et al. In vivo tracking of platelets; circulating degranulated platelets rapidly lose surface P-selectin but continue to circulate and function. Proc Natl Acad Sci U S A 1996;93:11877-82.

\section{Appendix}

Platelet cryopreservation method. In brief, apheresed platelets were collected with a continuous-flow centrifugation system (Fenwal CS 3000, with the PLT chamber or the TNX-6 chamber; Baxter Healthcare, Deerfield, Ill). Anticoagulant citrate dextrose (ACD) was used as the anticoagulant at a ratio of 1 volume of ACD to between 8 and 11 volumes of blood. A 50 to $75 \mathrm{~mL}$ volume of $27 \%$ dimethyl sulfoxide in saline solution was added to the platelets contained in the $1000 \mathrm{~mL}$ polyvinyl chloride platelet-freezing bag system (Fenwal 4R2986) to achieve a final dimethyl sulfoxide concentration of $6 \%$. The platelets were placed in an aluminum container, frozen at a rate of $2^{\circ}$ to $3^{\circ} \mathrm{C} / \mathrm{min}$, and then stored at $-80^{\circ} \mathrm{C}$ in a mechanical freezer. Platelets were 
collected and frozen at University of Massachusetts Medical Center (Worcester, Mass) and then transported frozen, packed in dry ice, to the Naval Blood Research Laboratory (Boston), where they were stored at $-80^{\circ} \mathrm{C}$. As needed, the frozen platelets from each $\mathrm{ABO}$ type were transported, again on dry ice, to the West Roxbury Veterans Administration Medical Center, where they were stored at $-80^{\circ} \mathrm{C}$ in a mechanical freezer until they were thawed, washed, resuspended, and stored in ACD plasma at $22^{\circ} \mathrm{C}$ for as long as 5 hours before infusion.

Liquid-preserved platelets. Pooled platelets were prepared from units of whole blood collected into citrate-phosphate-dextrose anticoagulant that had been stored at room temperature for no longer than 8 hours before platelet isolation. The whole blood was centrifuged ( $2000 \mathrm{~g}$ for 3 minutes) and the platelet-rich plasma was expressed into the attached transfer pack. The platelet-rich plasma was then centrifuged ( $5000 \mathrm{~g}$ for 5 minutes) and all but 35 to $70 \mathrm{~mL}$ of the plateletpoor plasma was expressed into the second transfer pack. The concentrated platelets were stored undisturbed at $22^{\circ} \mathrm{C}$ for 1 hour before resuspension. The resuspended platelets were stored in CLX bags in incubators maintained at $22^{\circ} \pm 2{ }^{\circ} \mathrm{C}$ with rotation for as long as 5 days before pooling. No longer than 4 hours before use, 5 to 7 units of platelets of the same $\mathrm{ABO}$ group were pooled in a $300-\mathrm{mL}$ transfer pack or 8 to 10 units were pooled in $600-\mathrm{mL}$ transfer pack.

Apheresed platelets were collected with a continuous-flow centrifugation system (Fenwal CS3000 with PLT chamber). ACD (National Institutes of Health formula A) was used as the anticoagulant at a ratio of 1 volume of ACD to 10 volumes of blood. The apheresed platelets were stored for as long as 5 days in $300 \mathrm{~mL}$ plasma in $1000-\mathrm{mL}$ CLX plastic bags ${ }^{*}$ in incubators maintained at $22^{\circ} \pm 2^{\circ} \mathrm{C}$ with rotation.

Platelet aggregation in response to arachidonic acid and adenosine diphosphate. ${ }^{15}$ In vitro studies were done with fresh, liquid-preserved, and previously frozen apheresis products. The platelet count for the in vitro testing was adjusted to $5.0 \times 10^{8} / \mathrm{mL}$ with autologous platelet-poor-plasma and measured with an automated particle counter (Coulter Model JT). A $50 \mu \mathrm{L}$ combination of $0.5 \mathrm{mg} / \mathrm{mL}$ AA and 20 $\mu \mathrm{mol} / \mathrm{L}$ ADP was added to $450 \mu \mathrm{L}$ diluted platelets (final concentrations $50 \mu \mathrm{g} / \mathrm{mL}$ AA and $2 \mu \mathrm{mol} / \mathrm{L}$ ADP). The platelet aggregation pattern was recorded for 5 minutes. The patterns were analyzed by digitizing the area under the curve with the Kurta Is/ONE input system (Kurta Corp, Phoenix, Ariz) and the data were reported as digitizer units for the 5minute period of aggregation.

Thromboxane $B_{2}$ assay. ${ }^{21}$ Thromboxane $\mathrm{B}_{2}$ was measured with a commercially available radioimmunoassay (New England Nuclear, Boston, Mass). Baseline levels of throm-

${ }^{*}$ CLX $=$ Tri(2)-ethylhexyl trimellitate (Cutter Laboratories, Berkeley, Calif). boxane were measured in the cell-free plasma, prepared by centrifuging a $450-\mu \mathrm{L}$ sample with $50 \mu \mathrm{L}$ of saline solution and $0.02 \mathrm{ng} / \mathrm{mL}$ ibuprofen at $1650 \mathrm{~g}$ for 10 minutes. The cellfree plasma samples were frozen at $-80^{\circ} \mathrm{C}$ until assay. In addition, production of thromboxane $\mathrm{B}_{2}$ per platelet was measured in the supernatant after aggregation with a combination of 50 $\mu \mathrm{g} / \mathrm{mL}$ AA and $2 \mu \mathrm{mol} / \mathrm{L}$ ADP. After 5 minutes of aggregation, ibuprofen $(0.02 \mathrm{ng} / \mathrm{mL}$ final concentration) was added to the cuvette to arrest thromboxane production and the sample was placed on ice. The sample was then centrifuged $(1650 \mathrm{~g}$ at $4^{\circ} \mathrm{C}$ for 10 minutes) and the plasma was frozen at $-80^{\circ} \mathrm{C}$ until assay as described previously. The thromboxane production per platelet was calculated as follows:

Thromboxane production per platelet $(\mathrm{pg})=$ (Aggregated thromboxane $B_{2}$ value $[p g]$ - Baseline thromboxane $B_{2}$ value [pg]) / (Platelet count) / $0.1 \mathrm{~mL}$

Platelet recovery from hypotonic stress. ${ }^{25}$ Platelet counts were measured with an automated particle counter (Coulter model JT). Response of the platelets to hypotonic stress was determined with a Philips PU 8800 UV/VIS spectrophotometer (Philips Electronic Instruments, Inc, Mahwah, NJ). Both test and reference positions of the spectrophotometer were zeroed at the same time with $600 \mu \mathrm{L}$ cell-free plasma and 300 $\mu \mathrm{L}$ saline solution. A $600-\mu \mathrm{L}$ sample of the diluted apheresis product and a $300-\mu \mathrm{L}$ volume of saline solution were placed in the test position and baseline optical density was recorded. A second $600-\mu \mathrm{L}$ sample of apheresis product and a $300-\mu \mathrm{L}$ volume of water were placed in the test position and the optical density was recorded for 10 minutes. Percentage recovery from hypotonic stress was calculated as follows:

Recovery from hypotonic stress $(\%)=[($ Secondary decrease in transmittance for 10 minutes) / (Initial increase in transmittance) $] \times 100 \%$

Plasma $\mathrm{pH}$. Nondiluted platelet pheresis product samples were kept in sealed plastic test tubes at $22^{\circ} \mathrm{C}$ until the $\mathrm{pH}$ measurement was made. Measurements were made on an Orion $\mathrm{SA}$ (model 520A) pH meter (Orion Research, Inc, Boston, Mass) equipped with an Omega silver-silver chloride electrode (Omega PHB-G2; Omega Engineering, Inc, Stamford, Conn).

Procoagulant activities of fresh, liquid-preserved, and cryopreserved platelets. This determination was performed as previously described elsewhere. ${ }^{30}$ Procoagulant activity was determined by flow cytometric analysis of the platelet binding of the coagulation factor $\mathrm{V}$-specific monoclonal antibody V237. Platelets were stimulated $\left(10\right.$ minutes at $\left.37^{\circ} \mathrm{C}\right)$ either with thrombin $(2 \mathrm{U} / \mathrm{mL})$, collagen $(20 \mu \mathrm{g} / \mathrm{mL})$, and calcium chloride $(3 \mathrm{mmol} / \mathrm{L})$, with calcium chloride $(3 \mathrm{mmol} / \mathrm{L})$, or with buffer alone. Values were expressed as the percentage of maximal V237 binding, as determined by the effect on fresh platelets of the calcium ionophore A23187 $(40 \mu \mathrm{mol} / \mathrm{L})$ and calcium chloride $(3 \mathrm{mmol} / \mathrm{L})$. 